\title{
Differences in dental caries experience between diabetic adolescents and healthy controls
}

\author{
Rusmira Fazlić1* , Amina Huseinbegović², Sniježana Hasanbegović3 , Mediha Selimović Dragaš²
}

'Dental Department, Health centre of Sarajevo Canton, Sarajevo, Bosnia and Herzegovina, ${ }^{2}$ Department of Preventive and Pediatric dentistry, School of Dental Medicine, University of Sarajevo, Sarajevo, Bosnia and Herzegovina, ${ }^{3}$ Endocrinology Department of Pediatrics, University Clinical Centre Sarajevo, Sarajevo, Bosnia and Herzegovina

\begin{abstract}
Introduction: While the influence of type 1 diabetes mellitus (T1DM) on periodontal health is well established, results of previous studies regarding the association of this metabolic disease and caries experience are rather inconsistent. The aim of this study was to assess the differences between caries status of healthy and adolescents with T1DM, as well as to determine the differences in caries experience among diabetic patients in relation to their metabolic control.
\end{abstract}

Methods: Assessment of caries status was performed using the DMFT index (decayed, missing, and filled teeth). The study group (Diabetic) included 60 patients diagnosed with T1DM, aged 12-18 years, from Sarajevo Canton. This group was divided into two sub-groups: A sub-group Diabetic-W consisted of 30 patients with well-controlled glycaemia, while a subgroup Diabetic-P comprised of 30 patients with poorer glycemic control. The control group consisted of 30 age-matched metabolically healthy individuals.

Results: The T1DM adolescents had a significantly higher $(p<0.01)$ mean DMFT score than the healthy subjects, 11.49 and 6.19 respectively. Statistically, the diabetic group had also significantly higher values of the D and $M$ components. Concerning the metabolic control, mean DMFT score in the Diabetic-W subgroup was lower (10.57) than in the Diabetic-P subgroup (12.39), however the difference was not statistically significant.

Conclusions: The results demonstrate that the T1DM patients have a higher caries experience, regardless of the degree of metabolic control. The level of untreated dental decay and missing teeth components among the diabetic adolescents indicates irregular dental attendance.

Keywords: type 1 diabetes mellitus; HbA1c; DMFT; adolescents

\section{INTRODUCTION}

Diabetes mellitus is a group of metabolic diseases characterized by elevated blood glucose levels

*Corresponding Author: Rusmira Fazlić, Dental Department, Health centre of Sarajevo Canton, (DZ Novo Sarajevo) Bihaćka 1, Sarajevo, Bosnia and Herzegovina, Phone: +387 61809 346,

E-mail: irma95@bih.net.ba.

Submitted: 21 February 2016 / Accepted: 12 April 2016

DOI: http://dx.doi.org/10.17532/jhsci.2016.334

UNIVERSITY OF SARAJEVO

FACULTY OF HEALTH STUDIES (hyperglycemia) resulting from defects in insulin secretion, insulin action, or both. In type 1 diabetes (T1DM), the body does not produce insulin. This type of diabetes is usually diagnosed during childhood or early adolescence (1). Complications of diabetes mellitus are the result of persistent hyperglycemia and poor metabolic control. Metabolic disturbances cause blood vessels damage and the main complications of diabetes mellitus affect the organs and tissues rich in 
capillary vessels, such as the kidney, retina, and nerves $(2,3)$.

Oral complications of diabetes mellitus include periodontal diseases (periodontitis and gingivitis); salivary dysfunction leading to a reduction in salivary flow and changes in saliva composition, and taste dysfunction. Oral fungal and bacterial infections have also been reported in patients with diabetes $(4,5)$. Reduced amount of saliva in diabetics decreases its antimicrobial activity. The oral cavity is therefore devoid of natural protection and prone to tooth decay and inflammation of the oral mucosa. Normal saliva has the anticariogenic effect - namely, in addition to calcium and phosphate ions, which play a role in teeth remineralisation, saliva contains components that destroy and inhibit the metabolism of cariogenic bacteria. The reduction of saliva secretion thus results in reduced resistance to the development of dental caries (4). Also, a high level of glucose in the saliva increases the amount of fermentable carbohydrates available for the metabolism of oral bacteria, which results in high production of acids that cause demineralization of hard tooth tissues. A higher concentration of salivary glucose and increased acidity in the mouth are the factors that lead to increased risk for the development of caries in patients with diabetes mellitus, while on the other hand, cutting back on carbohydrates and successful glycemic control can lead to a reduced incidence of caries in these patients (6).

Glycated hemoglobin A1c (HbA1c) is a widely used marker of chronic glycaemia, reflecting average blood glucose levels over a 2-3 month period of time. The test plays a critical role in the management of the patient with diabetes, since it correlates well with both microvascular and, to a lesser extent, macrovascular complications and is widely used as the standard biomarker for the adequacy of glycemic management $(7,8)$.

The aim of this study was to assess the differences between dental caries status of healthy and adolescents diagnosed with type 1 diabetes mellitus, as well as to determine whether there are differences in caries experience among diabetic patients in relation to their metabolic control.

\section{METHODS}

This is a prospective study conducted in the Public Institution Health Centre of Sarajevo
Canton (PIHCSC) from January 2014 to February 2015.

\section{Ethical considerations}

The study design was approved by the Ethical Committee of Dental Faculty, University of Sarajevo. The nature and purpose of the research was presented to the parents/guardians of all the subjects who participated in the study, and consequently consent forms were signed. At the end of the research, all the patients received adequate dental treatment.

\section{Subjects}

\section{Diabetic group}

Sixty patients (age 12 to 18) of the Endocrinology Department of Pediatric Clinic (EDPC) in Sarajevo, with type 1 diabetes, were included as subjects in this study. The patients who visited the EDPC for routine check-ups, during the period January 2014 - February 2015, were handed written information about the study, and the invitation for dental examination. During the study recruitment period, a total of 30 patients with poor metabolic control (subgroup Diabetic-P), who matched inclusion criteria, accepted to participate in the study. They were scheduled for the dental examination at the Dental Department of the Public Institution Health Centre of Sarajevo Canton (DDPIHCS). Another consecutively attending 30 subjects with well-controlled glycaemia (subgroup Diabetic-W), who accepted to participate in the study and matched the criteria, were scheduled for the examination. The degree of diabetes control was assessed by glycated hemoglobin (HbA1c). Well-controlled diabetics had HbA1c $\leq 7 \%$, whereas poor control was considered when HbA1c > 7\% $(7,8)$. This information was obtained from the patient medical records.

Besides the written parental consent and age, participants were selected by the inclusion criteria of being patients diagnosed with T1DM according to the diagnostic protocol of the EDPC in Sarajevo, at least 2 years earlier. The exclusion criteria were: subjects undergoing active orthodontic therapy, having extensive and multiple non-carious lesions of hard tooth tissues, and having professionally applied topical fluorides in the previous 6 months. 


\section{Control group}

Upon selection of diabetic participants, 30 metabolically healthy adolescents of corresponding age, who consecutively attended the DDPIHCS for dental check-ups and agreed to participate in the study, were recruited. The inclusion criteria for controls were: age, parental consent, and no history of systemic illness. The exclusion criteria were the same as those for the Diabetic group.

\section{Dental examinations}

Clinical examinations were performed at the DDPIHCS, by a single dentist, using a straight dental mirror and dental probe.

Dental status was assessed by using the DMFT index according to the World Health Organization (WHO) guidelines (9). The DMFT Index is used to describe the prevalence of dental caries in an individual by scoring decayed - untreated carious teeth, missing, and filled teeth. "D" component included teeth with clearly visible caries lesions with cavitation; "M" denoted extracted teeth due to caries, whereas " $F$ " denoted teeth with definitive filling.

\section{Statistical analysis}

Data were analyzed using Microsoft Office XP Excel. DMFT score and its components were calculated. Differences between the groups were assessed by using the Student $t$-test. Differences were considered to be statistically significant at $\mathrm{p}<0.05$.

\section{RESULTS}

The subjects in the study were aged $12-18$ years. The Diabetic group consisted of 60 subjects with T1DM, mean age $15.8 \pm 1.79$ years, whereas in the Control group there were 30 healthy subjects, mean age $15.2 \pm 1.99$ years. The mean age of the subjects from the Diabetic-W subgroup was $15.97 \pm 1.59$ years, whereas of those with poor metabolic control from the Diabetic-P subgroup was $15.63 \pm 1.99$ years.

Average duration of the illness in the Diabetic-W subgroup was $8.87 \pm 3.13$ years, and in the Diabetic-P subgroup it was $8.37 \pm 3.12$ years. This is not regarded as statistically significant difference.

The proportion of caries-free participants in the Diabetic group is somewhat higher than in the Control group as shown in Figure 1.
The diabetic adolescents had a significantly higher ( $p<0.01, t$-test) mean DMFT score than the healthy subjects, which are $11.49 \pm 3.10$ and $6.19 \pm 2.54$ respectively. The mean number of decayed teeth (DT) was significantly lower $(\mathrm{p}<0.01)$ in the Control group compared to the Diabetic group.

There were fewer extracted teeth (MT) among the metabolically healthy adolescents compared to the diabetic subjects, and this result is statistically significant $(\mathrm{p}<0.01)$.

The mean number of filled teeth (FT) is statistically $(\mathrm{p}<0.05)$ lower in the Control group compared to the Diabetic group, as shown in Figure 2.

In terms of metabolic control, mean DMFT score in the Diabetic-W subgroup was $10.57 \pm 3.22$, which was lower than in the Diabetic-P subgroup

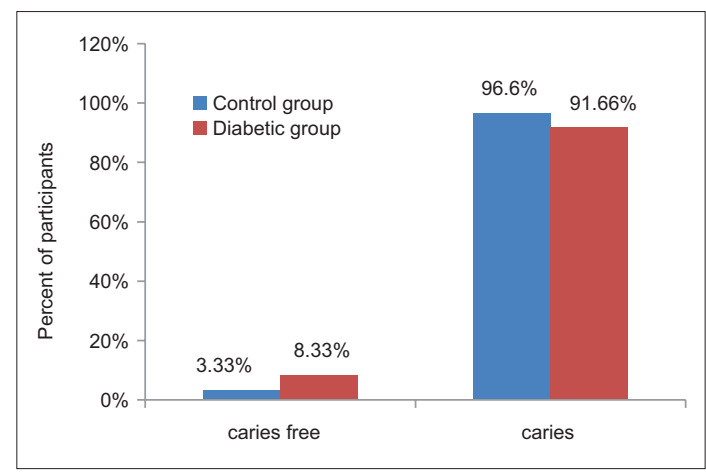

FIGURE 1. Proportion of caries-free versus caries-active participants.

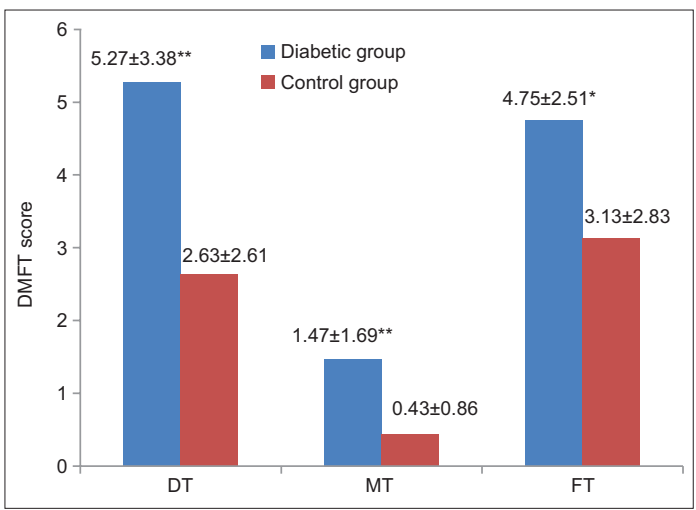

FIGURE 2. Means of DMFT components in Diabetic and Control groups. DT= decayed teeth; $M T=$ missing teeth; $F T=$ filled teeth . ${ }^{* *} p<0.01$ (t-test); ${ }^{*} p<0.05$ (t-test). 
$(12.39 \pm 2.97)$, but the difference is not statistically significant.

A positive correlation was found only between the level of control of T1DM and mean number of extracted teeth. The adolescents with better metabolic control showed statistically less extracted teeth, than those with poorer control $(\mathrm{p}<0.05)$.

No significant statistical differences in terms of caries and filled teeth were found between the subjects in the Diabetic-W and Diabetic-P subgroups. The results are shown in Figure 3.

\section{DISCUSSION}

The overall results of this study demonstrate poor dental health status in both healthy and adolescents with T1DM. In line with the WHO criteria, the mean DMFT $(6.19 \pm 2.54)$ in our Control group is considered to be of high severity level (10). Due to relatively small sample size and recruitment among adolescents with regular dental attendance, the sample cannot be regarded representative of the entire population. However, since an earlier study, conducted on national and regional levels in Bosnia and Herzegovina, reported a DMFT score of 7.6 \pm 4.0 and only $2 \%$ caries-free subjects among 15-yearolds in Sarajevo, in 2007 (11), the results from our study strongly suggest that there is an urgent need for community-based strategies for caries disease control in Sarajevo.

While periodontal disease is a well-documented complication of T1DM $(5,12)$, the relationship between this metabolic disease and dental caries is still

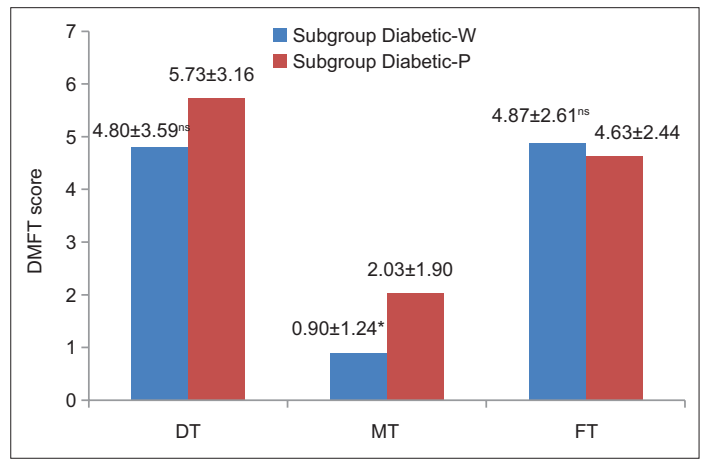

FIGURE 3. Means of DMFT components with regard to metabolic control. $\mathrm{DT}=$ decayed teeth; $\mathrm{MT}=$ missing teeth; $\mathrm{FT}=$ filled teeth; ns $=$ not significant $\left(t\right.$-test); ${ }^{*} p<0.05$ (t-test). unclear. Earlier studies on this issue reported inconsistent results. In a systematic review of oral health status of adolescents with T1DM in relation to caries in the permanent dentition (DMFT/S), Ismail et al. reported 5 studies indicating significantly higher caries experience in children with type 1 diabetes when compared to healthy controls, 3 studies indicating significantly lower values, and 7 studies reporting no difference between the two groups (13).

While salivary secretion dysfunction, as documented in several studies on diabetic patients (5), increases a caries risk, a proper metabolic control prevents the high glucose content and lower $\mathrm{pH}$ of saliva. Also, proper diabetic diet, rich in fibre and low in simple carbohydrates, may slow down the production of plaque and the proliferation of acidogenic bacterial microflora (3). Regarding the amount of Streptococcus mutans or Lactobacilli that represent a considerable risk factor in caries development, findings of previous studies are controversial. While studies of Swanljung et al. (14) and Twetman et al. (15) found significantly larger amounts of those bacteria in diabetic patients compared to controls, Siudikiene et al. (16), El-Tekeya et al. (17), and Canepari et al. (18) found that a mean $\log$ count of microorganisms between studied groups was not significantly different.

The proportion of caries-free diabetics in our study was somewhat greater compared to the Control group, and this result is opposed to the results obtained by Alavi et al. (19). In terms of caries experience, though, our results showed that the diabetic adolescents had a significantly higher mean DMFT score than the controls. Other studies $(15,20,21)$ also demonstrated higher scores in patients with diabetes mellitus. However, a few other studies suggest that there are practically no differences between the two groups $(17,22)$.

Regarding DMFT components, multiple studies $(3,23,24)$ found a higher rate of decayed teeth in patients with diabetes mellitus compared to healthy children, which is in accordance with our results. The study of Miko et al. (25) showed no statistical difference in that regard. Arheiam and Omar reported that the mean number of decayed and missing teeth was higher in diabetic children (26). Our results also demonstrated a higher rate of missing, as well as filled teeth in the diabetic children. 
When the correlation between the level of metabolic control of T1DM and dental condition is considered, most of the studies report that well-controlled diabetics have fewer decayed teeth. In our study, the mean DMFT value in the subjects from the Diabetic-P subgroup was greater compared to the well-controlled patients, however, the difference is not statistically significant. This is in accordance with a study performed by El-Tekeya et al. (17), which indicated no significant difference between well, fairly, and inadequately controlled patients regarding caries experience.

However, the subjects with poorer metabolic control in our study had a significantly higher rate of extracted teeth.

As opposed to ours and the results of El-Tekeya et al., the main finding of the study conducted by Tweetman et al. (6) was that diabetic children and adolescents with poor metabolic control developed 3 times more lesions during the study period compared to those with better metabolic control. The results of Miko et al. (25) also showed that the mean number of decayed teeth in well-controlled T1DM adolescents is lower, but the number of filled teeth is higher than in patients with poorer glycemic control. Carneiro et al. (27) demonstrated that the DMFT score was higher in individuals with higher $\mathrm{HbAlc}$ values and that more caries-free individuals were found in the group with lower HbAlc. In the study of Sudikiene et al. (28), well to moderately controlled diabetics had fewer decayed surfaces. Orbak et al. (3) found that the incidence of caries in permanent dentition was higher in the group with poor metabolic control.

Although the sample in this study is not representative and the results cannot be applicable to the entire population of this age, we believe that the study findings provide enough evidence to suggest possible association between diabetes mellitus and increasing dental caries in adolescent population in Sarajevo. To draw definitive conclusions on this issue, complex interactions of multiple factors such as a reduced salivary flow rate and buffer effect, oral microbial counts, plaque accumulation, diet quality, but also health behaviors and socio-demographic factors, should be explored in a representative sample of subjects with and without diabetes.

\section{CONCLUSION}

Within the limitations of the study, presented results clearly demonstrate that young patients with type 1 diabetes mellitus have a significantly greater caries experience than their healthy counterparts, regardless of the degree of metabolic control. Furthermore, the level of untreated dental decay as well as missing teeth among the diabetic adolescents is very high, which indicates irregular dental attendance. A joint action of both dental and non-dental health professionals is needed to raise the awareness about oral health complications associated with diabetes. In order to receive timely and adequate oral health advice and care, pediatric patients and their parents should be referred to the dentist at the very onset of the disease.

\section{CONFLICT OF INTEREST}

The authors declare no conflict of interest.

\section{REFERENCES}

1. Loghmani E. Diabetes mellitus: type 1 and type 2. In: Stang J, Story M, editors. Guidelines for adolescent nutrition services. Minneapolis, MN: Center for Leadership, Education and Training in Maternal and Child Nutrition, Division of Epidemiology and Community Health, School of Public Health, University of Minnesota; 2005. p. 167-82.

2. Forbes JM, Cooper ME. Mechanisms of diabetic complications. Physiol Rev. 2013;93(1):137-88.

http://dx.doi.org/10.1152/physrev.00045.2011.

3. Orbak R, Simsek S, Orbak Z, Kavrut F, Colak M. The influence of type-1 diabetes mellitus on dentition and oral health in children and adolescents. Yonsei Med J. 2008:49(3):357-65.

http://dx.doi.org/10.3349/ymj.2008.49.3.357.

4. Ben-Aryeh H, Serouya R, Kanter $Y$, Szargel R, Laufer D. Oral health and salivary composition in diabetic patients. J Diabetes Complications. 1993;7:57-62.

http://dx.doi.org/10.1016/1056-8727(93)90025-T.

5. Al-Maskari AY, Al-Maskari MY, Al-Sudairy S. Oral manifestations and complications of diabetes mellitus. A review. Sultan Qaboos Univ Med J. 2011;11(2):179-86.

6. Twetman S, Johansson I. Birkhed D, Nederfors T. Caries incidence in young type 1 diabetes mellitus patients in relation to metabolic control and caries-associated risk factors. Caries Res. 2002;36(1):31-5.

http://dx.doi.org/10.1159/000057587

7. International Expert Committee. International Expert Committee report on the role of the $\mathrm{A} 1 \mathrm{C}$ assay in the diagnosis of diabetes. Diabetes Care. 2009;32:1327-34

http://dx.doi.org/10.2337/dc09-9033.

8. American Diabetes Association. Diagnosis and classification of diabetes mellitus. Diabetes Care. 2012;35(Suppl 1):S64-71.

http://dx.doi.org/10.2337/dc12-s064.

9. World Health Organization. Oral health surveys: basic methods. $4^{\text {th }}$ ed Geneva: World Health Organization; 1997. 
10. Petersen PE. Oral health. In: Heggenhougen K, Quah S, editors. International encyclopedia of public health. Vol 4. San Diego: Academic Press; 2008. p. 677-85.

http://dx.doi.org/10.1016/B978-012373960-5.00527-X.

11. Marković N, Arslanagić-Muratbegović A, Kobašlija S, Bajrić E, SelimovićDragaš $M$, Huseinbegović $A$. Caries prevalence of children and adolescents in Bosnia and Herzegovina. Acta Med Acad. 2013;42(2):108-16. http://dx.doi.org/10.5644/ama2006-124.79.

12. Lalla E, Cheng B, Lal S, Tucker S, Greenberg E, Goland R, et al. Periodontal changes in children and adolescents with diabetes: A case-control study. Diabetes Care. 2006;29(2):259-99.

http://dx.doi.org/10.2337/diacare.29.02.06.dc05-1355.

13. Ismail AF, McGrath CP, Yiu CK. Oral health of children with type 1 diabetes mellitus: a systematic review. Diabetes Res Clin Pract. 2015;108(3):369-81. http://dx.doi.org/10.1016/j.diabres.2015.03.003.

14. Swanljung O, Meurman JH, Torkko H, Sandholm L, Kaprio E, Maenpaa J. Caries and saliva in 12-18 year-old diabetics and controls. Scand J Dent Res. 1992;100(6):310-13.

http://dx.doi.org/10.1111/j.1600-0722.1992.tb01077.x.

15. Twetman S, Aronsson S, Bjorkman S. Mutans streptococci and lactobacilli in saliva from children with insulin dependent diabetes mellitus. Oral Microbiol Inmunol. 1989;4:165-8.

http://dx.doi.org/10.1111/j.1399-302X.1989.tb00245.X.

16. Siudikiene J, Machiulskiene V, Nyvad B, Tenovuo J, Nedzelskiene I. Dental caries increments and related factors in children with type 1 diabetes mellitus. Caries Res. 2008:42:354-62.

http://dx.doi.org/10.1159/000151582.

17. El-Tekeya M, El Tantawi M, Fetouh H, Mowafy E, Khedr NA. Caries risk indicators in children with type 1 diabetes mellitus in relation to metabolic control. Pediatr Dent. 2012;34(7):510-16.

18. Canepari P, Zerman N, Cavalleri G. Lack of correlation between salivary Streptococcus mutans and lactobacilli counts and caries in IDDM children. Minerva Stomatol. 1994;43(11):501-5.
19. Alavi AA, Amirhakimi E, Karimi B. The prevalence of dental caries in 5-18 year-old insulin-dependent diabetic of Fars Province, Southern Iran. Arch Iran Med. 2006;9(3)254-60.

20 Karjalainen KM, Knuuttila MLE, Kaar ML. Salivary factors in children and adolescents with insulin-dependent diabetes mellitus. Pediatr Dent. 1996;18(4):306-11.

21. Akpata ES, Alomari Q, Mojiminiyi OA, Al-Sanae H. Caries experience among children with type 1 diabetes in Kuwait. Pediatr Dent. 2012;34(7):468-72.

22. Alves C, Menezes R, Brandao M. Salivary flow and dental caries in Brazilian youth with type 1 diabetes mellitus. Indian J Dent Res. 2012;23:758-62. http://dx.doi.org/10.4103/0970-9290.111254.

23. Lopez del Valle LM, Ocasio-Lopez C. Comparing the oral health status of diabetic and non-diabetic children from Puerto Rico: a case-control pilot study. P R Health Sci J. 2011;30:123-27.

24. Tagelsir A, Cauwels R, van Aken S, Vanobbergen J, Martens LC.Dental caries and dental care level (restorative index) in children with diabetes mellitus type 1. Int J Pedriatic Dent. 2011;21(1):13-22.

http://dx.doi.org/10.1111/j.1365-263X.2010.01094.x.

25. Miko S, Ambrus SJ, Sahafian S, Dinya E, Tamas G, Albrecth MG. Dental caries and adolescenta with type 1 diabetes. Br Dent J. 2010;208(6):E12.

26. Arheiam A, Omar S. Dental caries experience and periodontal treatment needs of 10 - to 15 -year old children with type 1 diabetes mellitus. Int Dent J. 2014;64(3):150-4.

http://dx.doi.org/10.1111/idj.12091.

27. Carneiro VL, Fraiz FC, Ferreira Fde M, Pintarelli TP, Oliveira AC, Boguszewski MC. The influence of glycemic control on the oral health of children and adolescents with diabetes mellitus type 1. Arch Endocrinol Metab. 2015;59(6):535-40. http://dx.doi.org/10.1590/2359-3997000000117.

28. Siudikiene J, Machiulskiene V, Nyvad B, Tenovuo J, Nedzeiskiene I. Dental caries and salivary status in children with type 1 diabetes mellitus related to the metabolic control of the disease. Eur J Oral Sci. 2006;114:8-14.

http://dx.doi.org/10.1111/j.1600-0722.2006.00277.x 